\title{
Stakeholder Analysis of Data Ecosystems
}

\author{
Umair ul Hassan and Edward Curry
}

\begin{abstract}
Stakeholder analysis and management have received significant attention in management literature primarily due to the role played by key stakeholders in the success or failure of projects and programmes. Consequently, it becomes important to collect and analyse information on relevant stakeholders to develop an understanding of their interest and influence. This chapter provides an analysis of stakeholders within the European data ecosystem. The analysis identifies the needs and drivers of stakeholders concerning big data in Europe; furthermore, it examines stakeholder relationships within and between different sectors. For this purpose, a two-stage methodology was followed for stakeholder analysis, which included sector-specific case studies and a cross-case analysis of stakeholders. The results of the analysis provide a basis for understanding the role of actors as stakeholders who make consequential decisions about data technologies and the rationale behind the incentives targeted at stakeholder engagement for active participation in a data ecosystem.
\end{abstract}

Keywords Data ecosystem $\cdot$ Stakeholder analysis $\cdot$ Case study $\cdot$ Data value chain

\section{Introduction}

This chapter discusses the stakeholder analysis performed within the scope of the "Big data roadmap and cross-disciplinarY community for addressing socieTal Externalities" (BYTE ${ }^{1}$ ) project, between 2014 and 2017. The BYTE project analysed stakeholders in relation to data ecosystems as well as their relationships within and between different sectors. This analysis enabled the project to determine how to incentivise stakeholders to participate in its activities. The BYTE project was

\footnotetext{
${ }^{1}$ https://cordis.europa.eu/project/id/619551

U. ul Hassan $(\bowtie) \cdot$ E. Curry

Insight SFI Research Centre for Data Analytics, NUI Galway, Galway, Ireland

e-mail: umair.ulhassan@nuigalway.ie 
aimed at assisting European science and industry in capturing the positive externalities and diminishing the negative externalities associated with big data to gain a more significant market share. BYTE accomplished its goals by leveraging an international advisory board and an additional network of contacts to conduct a series of case studies. Each case study focused on big data practices across an industrial sector to gain an understanding of the economic, legal, social, ethical, and political externalities. A horizontal analysis was conducted to identify how positive externalities can be amplified and negative externalities diminished.

The rest of this chapter is organised as follows. Section 2 underlines the need for stakeholder analysis, and Sect. 3 defines a stakeholder in the context of the BYTE project. Sections 4 and 5 detail the methodology and dimensions of stakeholder analysis. Section 6 introduces the sector-wise case studies and the results of the cross-case analysis. Section 7 summarises the chapter.

\section{Stakeholder Analysis}

According to Grimble et al., "stakeholder analysis can be defined as an approach for understanding a system by identifying the key actors or stakeholders in the system and assessing their respective interest in that system" (Grimble et al. 1995). To map the relevant stakeholders within the European data ecosystem, the BYTE project started with industry contacts, academic experts, and civil society representatives active with big data, statistics, computer science, economics, open access, social science, and legal and ethical experts (Curry 2016). As the project progressed, industry and public sector representatives from the case study sectors, policymakers, institutional representatives, standards organisations, funding bodies, and any other relevant stakeholders were all engaged.

Grimble and Wellard have emphasised the importance of stakeholder analysis in understanding the complexity and compatibility problems between objectives and stakeholders (Grimble and Wellard 1997). Two questions must be answered before any stakeholder analysis: "Who is a stakeholder?" and "Why is their role needed?" To answer the first question, stakeholders are identified based on many factors, including their interest in and influence on a system, their knowledge about the system, and their networks internal and external to the system. With respect to the second question, it is also important to note that the roles played by stakeholders are dynamic rather than static over time. Depending on circumstances, the same people or groups can take on different roles at different times; furthermore, stakeholder roles may also be blended. It is also possible for stakeholders to move between roles, and specific actions can be targeted to "move" stakeholders from one role to another. 


\section{Who Is a Stakeholder?}

Stakeholder theory has become the mainstream of management literature across different disciplines since Freeman's seminal work on Strategic Management: A Stakeholder Approach (Freeman 1984). Within this work, the primary purpose of stakeholder theory was to assist managers in identifying stakeholders and strategically manage them. Freeman defines stakeholders as "any group or individual who can affect or is affected by the achievement of the organisation's objectives". Since this early work, stakeholder theory has been applied in many contexts and disciplines outside of management. Weryer describes it as a "slippery creature", "used by different people to mean widely different things" (Weyer 1996). Miles has established that stakeholder is an essentially contested concept, and therefore requiring a universal definition is unfeasible (Miles 2012). Nonetheless, it is essential to define stakeholder and provide the basis for necessary stakeholder analysis. The following definition of stakeholder was agreed and adopted after considering existing definitions in the literature and taking into account the objectives of the BYTE project:

A stakeholder is any group or individual who can affect or is affected by the information ecosystem in a positive or negative manner.

This definition served as the starting point to identify the stakeholders within each of the case studies. Subsequently, the same definition was used for analysis while following the methodology detailed in the next section.

\section{Methodology}

Both normative and instrumental approaches have been applied in different disciplines for stakeholder analysis. For instance, Reed et al. provide a comprehensive overview of the wide variety of techniques and approaches for stakeholder analysis (Reed et al. 2009). As illustrated in Fig. 1, they have categorised the methods used for: (i) identifying stakeholders, (ii) differentiating between and categorising stakeholders, and (iii) investigating relationships between stakeholders.

The stakeholder analysis within BYTE took place in two phases. The first phase focused on sector-specific case studies that built a logical chain of evidence to support the stakeholder analysis (Miles 2012; Yin 2013). The second phase involved a cross-case examination in identifying if generalities or commonalities existed across case studies. 


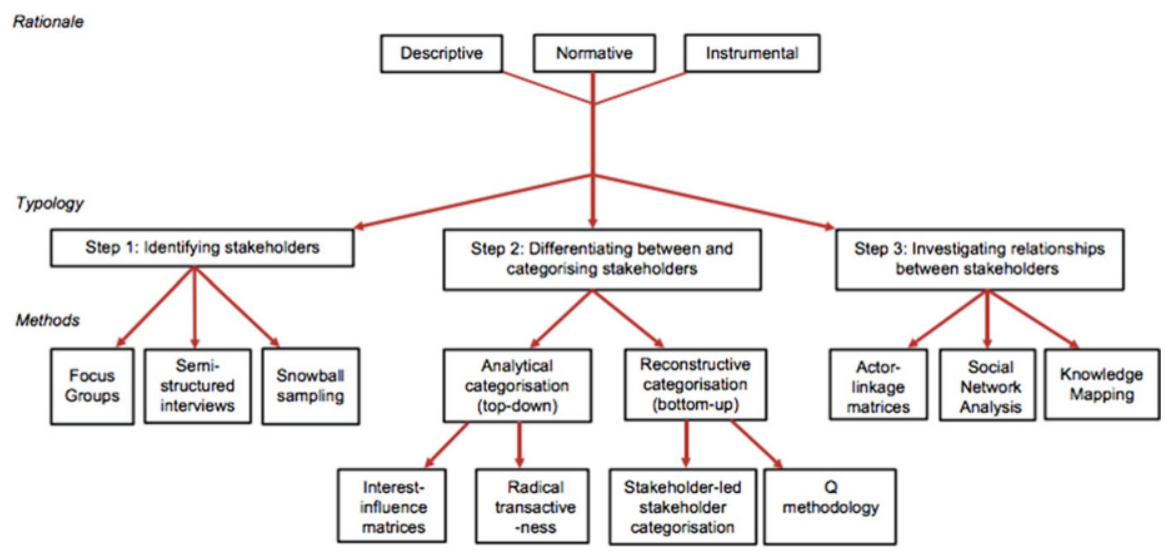

Fig. 1 Schematic representation of rationale, typology, and methods for stakeholder analysis (Reed et al. 2009). (Reprinted from Journal of Environmental Management, 90/5, Mark S. Reed, Anil Graves, Norman Dand, Helena Posthumus, Klaus Hubacek, Joe Morris, Christina Prell, Claire H. Quinn, Lindsay C. Stringer, Who's in and why? A typology of stakeholder analysis methods for natural resource management, 1933-1949., Copyright (2009), with permission from Elsevier.)

\subsection{Phase 1: Case Studies}

The first phase of stakeholder analysis includes eight steps, as follows:

1. Identify the focus of the case study: At the start of the case study, it is important to establish a clear focus. This defines the context of the case study and makes it possible to determine those who are affected or can affect decisions relating to the issues under investigation.

2. Identify the boundary of analysis of the case study: With a clear focus of the case study defined, the next step is to establish a clear system boundary for the stakeholder analysis. The system boundary is used to limit the scope of the analysis to ensure that it tackles the identified focus. Steps 1 and 2 may follow a participatory approach that involves the stakeholders directly in the identification of foci and boundaries. This necessitates an iterative feedback loop. It should be noted that stakeholder participation in the analysis may not be necessary if the project team have sufficient knowledge of the case study.

3. Identification of stakeholders and their stake (i.e. interviews, case studies, workshops): The project team, in collaboration with the case study liaisons, prepares a list of possible stakeholders for the case study. The stakeholders are listed according to the role that best describes their involvement in the case study (policymakers, data scientist, data engineer, managers, end-users, consultants, and consumers). The initial list can be as exhaustive as possible to ensure the inclusion of all relevant stakeholders in the case study. Once completed, the initial list is circulated to the key actors in the case study for feedback. The feedback is then used to add missing members or delete others who are not relevant. To 
provide a systematic tool for the identification of stakeholders in the complex context of case studies, Pouloudi has suggested a set of principles of stakeholder behaviour that guide stakeholder identification and analysis (Pouloudi 1999).

4. Differentiate between and categorise stakeholders: Several methods are available for categorising stakeholders and understanding their inter-relationships (Step 5). The project team classifies the list of stakeholders based on their interest in each case study. The initial classification is qualitative as it is based on the subjective judgement of the project team. To further validate the categories, feedback can be sought from the key actors in the case study. The categories should be dynamic as stakeholders' interests and influence can change over time, depending on the dynamicity of the environment. Stakeholders can also be placed in multiple categories.

5. Investigate relationships between stakeholders: Once stakeholders have been identified and classified, the next step is to understand what relationships exist between the stakeholders. Understanding the interplay between stakeholders can reveal common motivations, alliances, and conflicts that exist within and across cases. It can also help us understand the motivations of stakeholders, which can help to support their incentivisation.

6. Identify stakeholder incentivisation and communication plan: Before any initiatives are designed to engage stakeholders, it is crucial to identify the most relevant stakeholders within the case and ensure their participation in the analysis process. The engagement of stakeholders is time consuming and not a trivial issue. Many potential stakeholders within a case study may lack interest, whereas some may have strong (and specific) interests that could dominate the agenda. Careful consideration of stakeholder interests may persuade less interested stakeholders to join the process. For instance, civil society organisations can prove challenging to engage.

7. Feedback into Step 1 or Step 2: At the end of the process, the feedback received is input back into the process to improve the quality of the analysis. Typically, stakeholder analysis will take place over several iterations of the process. As the analysis is refined, it is important to consider issues such as the legitimacy, representation, and credibility of the analysis. Where additional stakeholders have been identified in the process, they should be included in the next iteration.

8. Engage stakeholders for validation: The last step of the process is the validation of the stakeholder analysis with a selected group of stakeholders. The validation takes the form of interviews with key actors within the case study and stakeholder engagement workshops. In these workshops, the project team directly works with stakeholders to elicit required input for validation and consensus, where possible, on the stakeholder analysis. At the beginning of the interview/workshop, the purpose of the stakeholder analysis is detailed to ensure that relevant stakeholders actively participate. The feedback is then used to update the stakeholder analysis, as necessary. 


\subsection{Phase 2: Cross-Case Analysis}

As part of the second phase, cross-case analysis is used to examine themes, similarities, and differences across several cases. It provides further insight into issues concerning the case and reveals the potential for generalising the case study results. Cross-case analysis can also be used to delineate the combination of factors that may contribute to the outcomes of the individual case. It can be used to determine an explanation as to why one case is different from or the same as others. Multiple cases are examined to build a logical chain of evidence to support the stakeholder analysis (Miles 2012; Yin 2013). The cross-case analysis consists of the following steps:

(i) Within-case stakeholder analysis

(ii) Analysis of consistencies identified across the cases in the various relationships, along with reasons why these relationships exist

(iii) Formulating systematic cross-case observations

\section{Sectoral Case Studies}

A key fallacy associated with big data is that the processing of large data sets will lead directly to either benefit or harm. However, economic experts have noted that data only becomes information once it guides strategy, motivates action, and leads to observable changes in behaviour. More information does provide strategic options with which to deal with strategic, environmental, or technical challenges. But these options require the correct environment to obtain a competitive advantage. Likewise, the capability to exploit information for harm does not guarantee that societal harm will occur. Expected harm can be minimised by ensuring the correct institutional or legal framework for addressing negative externalities of big data.

Through the Digital Agenda for Europe, European policymakers have expressed that they expect big data to result in positive competitive advantages across various sectors of the economy. At a high level, these sectors include transport, healthcare, environment, smart city, energy, crisis management, and culture. The BYTE project threaded case studies in these sectors through the course of the project, as listed in Table 1. These case studies involved organisations actively using big data for their operational and strategic purposes. The case studies enabled BYTE to understand strategies, actions, and changes in behaviour associated with big data, with the aim of identifying their resultant positive and negative externalities (Cuquet et al. 2017). Furthermore, they enabled BYTE to better predict the type of regulatory environment that would allow European actors to take advantage of potential positive externalities and diminish negative externalities. 
Table 1 List of stakeholders considered as part of the case studies in the BYTE project

\begin{tabular}{|c|c|c|}
\hline $\begin{array}{l}\text { Case study } \\
\text { sector }\end{array}$ & Stakeholder & Secondary sector \\
\hline \multirow[t]{3}{*}{ Crisis } & RICC & Computer science \\
\hline & International Government Organization (OCHA) & Humanitarian organisation \\
\hline & International Humanitarian Organization (ICRC) & Humanitarian organisation \\
\hline \multirow[t]{7}{*}{ Culture } & $\begin{array}{l}\text { National cultural heritage institutions, including } \\
\text { libraries, museums, galleries, etc. }\end{array}$ & Cultural \\
\hline & National data aggregator & Cultural \\
\hline & Pan-European cultural heritage data & Cultural \\
\hline & Policymakers and legal professionals & Government \\
\hline & Citizens & Citizens \\
\hline & Educational institutions & Public sector \\
\hline & Open data advocates & Society organisation \\
\hline \multirow[t]{6}{*}{ Energy } & Statoil & Oil \& gas operator \\
\hline & ConocoPhillips & Oil \& gas operator \\
\hline & Lundin & Oil \& gas operator \\
\hline & Eni Norge & Oil \& gas operator \\
\hline & SUPPLIER & Oil \& gas supplier \\
\hline & Norwegian Petroleum Directorate & $\begin{array}{l}\text { Oil \& gas regulator in } \\
\text { Norway }\end{array}$ \\
\hline \multirow[t]{9}{*}{ Environment } & EC & Public sector (EU) \\
\hline & EEA & Public sector (EU) \\
\hline & EPA & Public sector (USA) \\
\hline & EuroGeoSurveys & Public sector (EU) \\
\hline & EUSatCen & Public sector (EU) \\
\hline & IEEE & Professional association \\
\hline & NASA & Space (USA) \\
\hline & SANSA & Space (South Africa) \\
\hline & UNEP & Public sector \\
\hline \multirow[t]{9}{*}{ Healthcare } & Public sector health research initiative & $\begin{array}{l}\text { Healthcare, medical } \\
\text { research }\end{array}$ \\
\hline & Geneticists & $\begin{array}{l}\text { Healthcare, medical } \\
\text { research, }\end{array}$ \\
\hline & Clinicians & $\begin{array}{l}\text { Healthcare (private and } \\
\text { public) }\end{array}$ \\
\hline & Data scientists & $\begin{array}{l}\text { Healthcare, medical } \\
\text { research }\end{array}$ \\
\hline & Pharmaceutical companies & Commercial \\
\hline & Translational medicine specialists & $\begin{array}{l}\text { Healthcare (private and } \\
\text { public sector) }\end{array}$ \\
\hline & Public health research initiative & $\begin{array}{l}\text { Healthcare, translational } \\
\text { medicine specialist }\end{array}$ \\
\hline & NHS Regional genetics laboratory & $\begin{array}{l}\text { Public sector healthcare } \\
\text { laboratory }\end{array}$ \\
\hline & Charity organisations & Civil society organisations \\
\hline
\end{tabular}


Table 1 (continued)

\begin{tabular}{|c|c|c|}
\hline $\begin{array}{l}\text { Case study } \\
\text { sector }\end{array}$ & Stakeholder & Secondary sector \\
\hline & $\begin{array}{l}\text { Privacy and data protection policymakers and } \\
\text { lawyers }\end{array}$ & Public and private sector \\
\hline & Citizens & Society at large \\
\hline & Patients and immediate family members & Public sector \\
\hline \multirow[t]{9}{*}{ Transport } & Established ship owner & Transport \\
\hline & New ship owner & Transport \\
\hline & European yard & Manufacturing \\
\hline & Navigation equipment supplier & Manufacturing \\
\hline & Machinery subsystem supplier & Manufacturing \\
\hline & Shipping association & Transport \\
\hline & Maritime consulting company & Transport \\
\hline & Classification society & Transport/legal \\
\hline & Natl. Coastal Authority & Legal \\
\hline \multirow[t]{4}{*}{ Smartcity } & European city & Public sector \\
\hline & Technology provider & Start-up, energy \\
\hline & Technology provider & Non-profit, mobility \\
\hline & Technology provider \& research & Multinational, smart city \\
\hline
\end{tabular}

\section{Cross-Case Analysis}

This section specifies the dimensions used in the cross-case analysis of stakeholders. The relevance of the dimensions may vary between stakeholders and use cases. Based on the case studies described earlier, this section compares the stakeholders of the BYTE project. This cross-case analysis aims to identify the commonalities of stakeholders and highlight the differences (Lammerant et al. 2015). The analysis informed the activities of the BYTE project, including big data community formation and long-term stakeholder engagement.

\subsection{Technology Adoption Stage}

The diffusion of innovations is a theory that seeks to explain how, why, and at what rate new ideas and technology spread through cultures. The seminal work on this theory was undertaken by Everett Rogers (Rogers 1962). He describes diffusion as the process by which an innovation is communicated through specific channels over time among the members of a social system. Adoption implies accepting something created by another or foreign to one's nature. For a technology to be adopted by many users, it needs to be successfully diffused. Rogers describes the five adopters as follows: 
- Innovators are the first $2.5 \%$ of individuals to adopt an innovation. They are adventurous, comfortable with a high degree of complexity and uncertainty, and typically have access to substantial financial resources

- Early Adopters are the next $13.5 \%$ to adopt innovation. They are well integrated into their social system and have great potential for opinion leadership. Other potential adopters look to early adopters for information and advice. Thus early adopters make excellent "missionaries" for new products or processes

- Early Majority are the next 34\%. They adopt innovations slightly before the average member of a social system. They are typically not opinion leaders, but they frequently interact with their peers

- Late Majority are the next 34\%. They approach innovation with a sceptical air and may not adopt the innovation until they feel pressure from their peers. They may have scarce resources

- Laggards are the last $16 \%$. They base their decisions primarily on experience and possess almost no opinion leadership. They are highly sceptical of innovations and innovators and must feel confident that an innovation will not fail before adopting it.

In terms of technology adoption, the BYTE case studies highlight some specifics of and similarities between the stakeholders. As shown in Fig. 2, the stakeholders in these case studies follow the Rogers curve, i.e. $6 \%$ innovators, $21 \%$ early adopters, $33 \%$ early majority, $23 \%$ late majority, and 17\% laggards. Some sectors are more advanced in their adoption of data technologies. For instance, the stakeholders in smart cities and crisis management case studies are either early adopters or early majority. This underlines their natural dependence on data-driven decision-making and operations. Only the stakeholders in the environment case study included

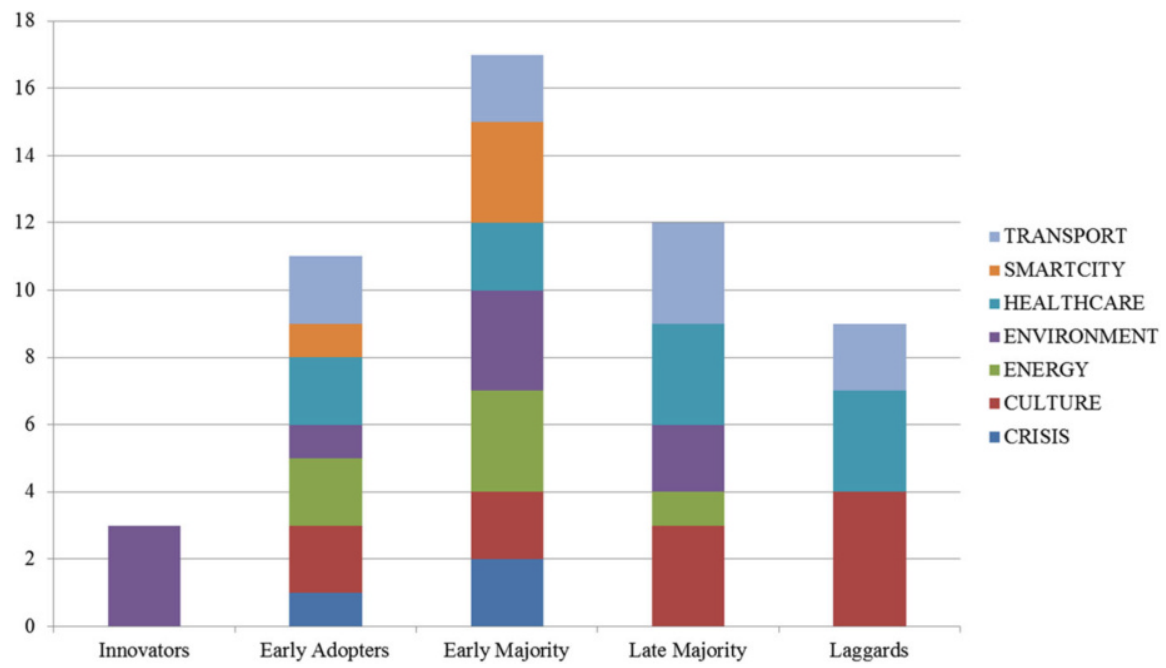

Fig. 2 Stakeholders against the technology adoption stages 
innovators that encompassed space agencies and technology standards organisations. The majority stakeholders in the transport, healthcare, and culture sectors fall in the late stages of technology adoption. Therefore, some stakeholder engagement activities can be tailored towards these sectors to encourage participation in the big data community and amplification of positive externalities. Late adoption might be due to higher regulatory standards or lower levels of technology readiness.

\subsection{Data Value Chain}

Value chains have been used as a decision support tool to model the chain of activities that an organisation performs to deliver a valuable product or service to the market. A value chain categorises the generic value-adding activities of an organisation, allowing them to be understood and optimised. A value chain is made up of a series of subsystems, each with inputs, transformation processes, and outputs. As an analytical tool, the value chain can be applied to the information systems to understand the value-creation of data technologies. The Data Value Chain models the high-level activities that comprise an information system. A typical data value chain comprises the following activities:

1. Data Acquisition is the process of gathering, filtering, and cleaning data before it is put in a data warehouse or any other storage solution on which data analysis can be carried out.

2. Data Analysis is concerned with making acquired raw data easy to use in decision-making as well as for domain-specific purposes.

3. Data Curation is the active management of data over its life cycle to ensure that it meets the necessary data quality requirements for its effective usage.

4. Data Storage is concerned with storing and managing data in a scalable way, satisfying the needs of applications that require access to the data.

5. Data Usage covers the business goals that require access to data and its analysis, and the tools needed to integrate analysis in business decision-making.

Figure 3 shows the distribution of the BYTE stakeholders in the activities associated with the Data Value Chain. Among the stakeholders analysed, 56\% explicitly consider the data acquisition activities, $56 \%$ perform some form of data analysis, $44 \%$ curate data, $40 \%$ are concerned with data storage solutions, and the majority of $88 \%$ actively use data for decision-making and operations. The crisis management sector has a primary focus on data usage, with minimal consideration for data acquisition and data analysis activities. The cultural sector is mainly focused on data acquisition, curation, and usage. Designing incentives that target the specific activities of the value chain can help engage with the relevant stakeholders. The sharing of best practices from stakeholders may also serve as an incentive for engagement with the big data community. Significantly, the stakeholders can share their expertise on one type of activity on the Data Value Chain with others. 


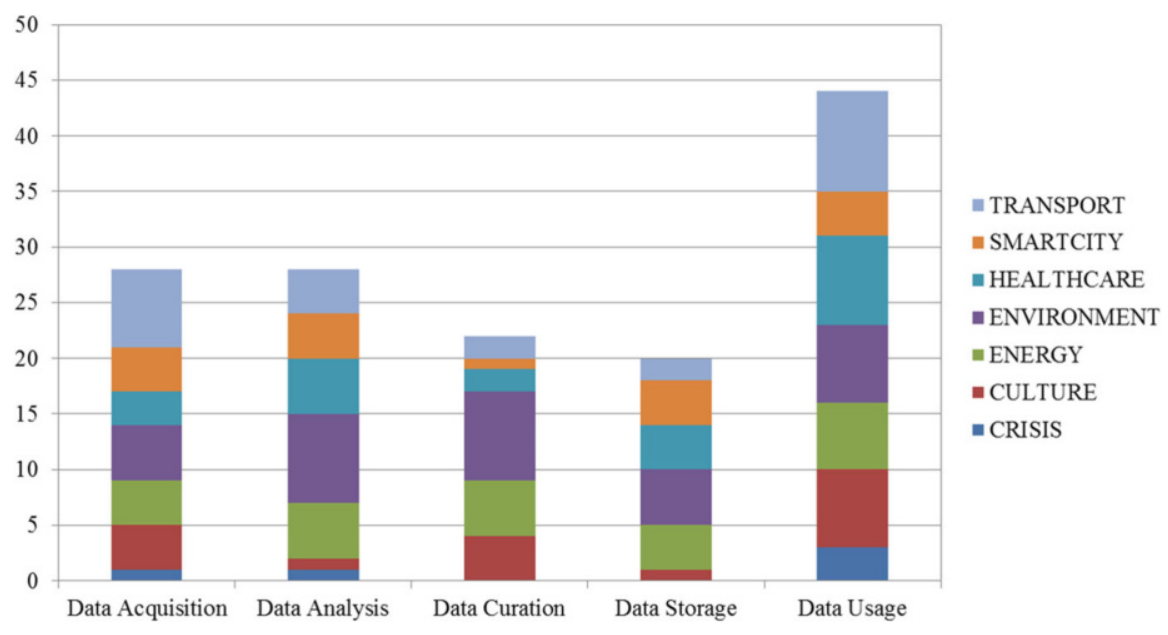

Fig. 3 Distribution of stakeholders in terms of activities on the Data Value Chain

\subsection{Strategic Impact of IT}

The strategic impact grid is an analytical tool proposed by Nolan and McFarlan that is used by managers to evaluate their firm's current and future information system's needs (Nolan and McFarlan 2005). The grid defines the use of information systems resources going forward, by enabling managers to:

- Identify the current need for reliable information systems by focusing on current day-to-day operations and the functionalities of the existing information systems

- Identify future needs for new information system functionalities by focusing on the strategic role that new IT capabilities play in the organisation

Based on this analysis, the grid helps managers to identify if they need to take a defensive or offensive approach in their information systems (IS) strategy. As depicted in Fig. 4, the grid classifies the approaches into four roles:

- Support Role: Information systems constitute a tool to support and enable operations. IS are not mission-critical for current business operations. New systems offer little strategic differentiation to significantly benefit the organisation.

- Factory Role: IS infrastructure is critical to the operation of the firm. Service outages can endanger the firm's well-being and future viability. However, limited potential exists for new systems and functionalities to make a substantial contribution to the firm.

- Turnaround Role: The firm's current IS are not mission-critical for current business operations. However, new IS functionalities will be critical for the business's future viability and success. The firm needs to engage in a transformation of its IT. 


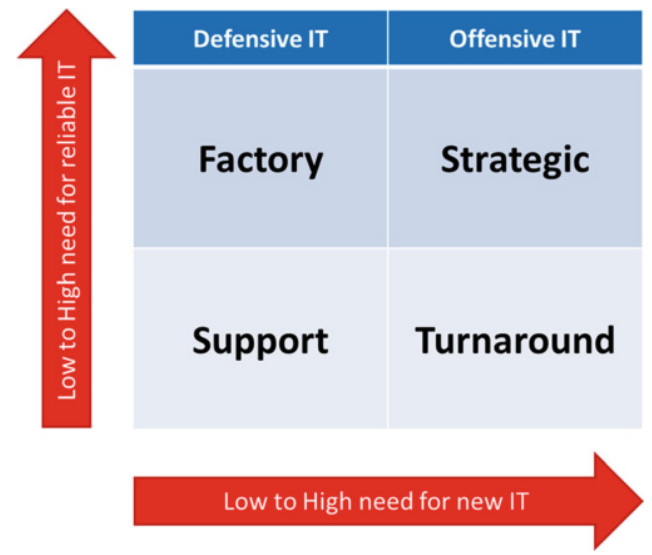

Fig. 4 Strategic Impact Grid
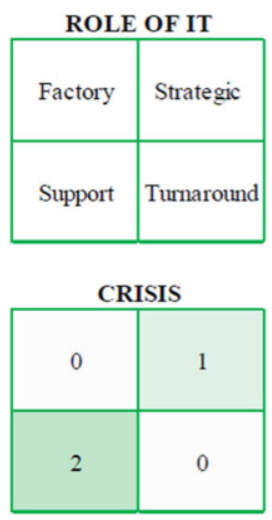
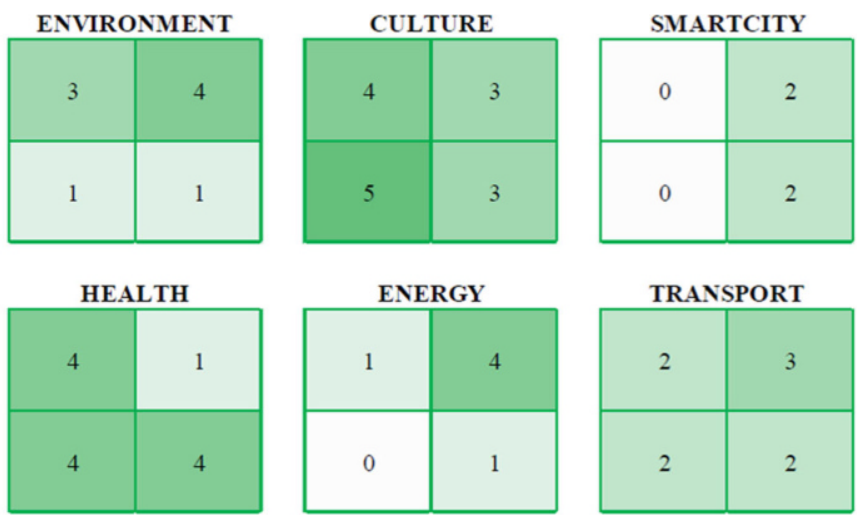

Fig. 5 Distribution of stakeholders on the Strategic Impact Grid

- Strategic Role: IS are critical to the firm's current business operations. New IS functionalities will be critical for the future viability and prosperity of the business. Such firms have a very offensive IT posture and are proactive concerning IT investments.

Figure 5 shows the distribution of the BYTE stakeholders on the Strategic Impact Grid. Among the stakeholders analysed, 18 stakeholders were identified as having a strategic role in IT. This highlights the need to balance engagement activities to encourage participation from stakeholders in the community in other roles, which may not consider big data to be critical to their decision-making and operations management. 
We also analysed the IT intensity of each case study as defined in a big data report published by McKinsey Global Institute (MGI) (Manyika et al. 2011). IT intensity indicates the ease of technology adoption and utilisation for a section. The report ranked the sectors according to their IT intensity and then divided them into five quantiles (first, second, third, fourth, fifth). The more IT assets a sector has on average, the easier it is to overcome barriers to data technologies. Each case study was mapped to the sectors indicated in the MGI report. The following list provides a summary of the analysis:

- Environment: The environment case study is mapped to the "Natural Resources" sector in the MGI report, which lies in the third quantile of IT intensity. The stakeholders in the environment case study are divided into distinct groups. The first group is focused on operations support and maintaining existing infrastructure, hence remaining in the factory role. The second group employs IT for strategic decisions and implements groundbreaking technologies, hence achieving the strategic role.

- Crisis Management: The crisis management case study is mapped to the "Health \& Social Care" sector in the MGI report, which lies in the fifth quantile of IT intensity. Crisis management stakeholders require more reliable IT processes due to the mission criticality of their operations.

- Smart City: The smart city case study is mapped to the "Utilities" sector in the MGI report, which lies in the second quantile of IT intensity. Stakeholders in the smart city case study indicated the need for offensive IT strategies. This is understandable due to the data-dependent nature of the businesses and services that enable the concept of the smart city.

- Culture: The smart city case study is mapped to the "Arts, Entertainment, and Recreation" sector in the MGI report, which lies in the second quantile of IT intensity. The stakeholders of the culture case study are interested in both reliable IT and innovative IT.

- Energy: The energy case study is mapped to the "Natural Resources" sector in the MGI report, which lies in the third quantile of IT intensity. For the stakeholders in the energy case study, the role of IT is primarily strategic for both business operations and competitive advantage.

- Health: The health case study is mapped to the "Healthcare and Social Assistance" sector in the MGI report, which lies in the fifth quantile of IT intensity. The stakeholders in the heath case study are more oriented towards reliable IT, which is a prerequisite of the health sector. However, there are stakeholders that are dependent on new tools for drug discovery and improved healthcare.

- Transport: The transport case study is mapped to the "Transportation and warehousing" sector in the MGI report, which lies in the first quantile of IT intensity. In the transport case study, we observe an even distribution of the role of IT on the Strategic Impact Grid. This indicates a balance between maintaining operations through big data and using big data to gain a competitive advantage. 


\subsection{Stakeholder Characteristics}

In addition to the dimensions introduced above, the stakeholder analysis captures a few additional attributes that are used to profile stakeholders. This section details these specific attributes and how they are represented for the purpose of analysis to establish the roles and communication needs of stakeholders. These attributes are as follows:

- Knowledge: Level of information and understanding possessed by the representative about the case study. This information is obtained by asking the representative a set of questions. Knowledge attribute could be expressed as a five-scale value: Very High, High, Average, Low, and Very Low.

- Position: Attitude and perspective of the representative towards the exercise, in terms of the degree of opposition or support expressed by the stakeholder representative. This attribute can be represented using a five-scale value: Supporter, Moderate Supporter, Neutral, Moderate Opponent, and Opponent.

- Interest: Level of interest shown by the representative in the case study, represented as a five-scale value: Very High, High, Average, Low, and Very Low.

In addition to the organisation-level analysis of stakeholder dimensions, the case studies also involved interviewing stakeholder individuals (or organisation representatives). The following figures show the distribution of stakeholders in terms of their knowledge, position, and interest (Figs. 6, 7, and 8).

Most stakeholders belong to the data providers and data users categories. This underlines the focus on the usage and exploitation of big data by the case studies. In general, the case study stakeholders rated high in terms of knowledge and interest, which could be attributable to the fact that each case study had an active big data solution. It also shows that the stakeholders across different sectors are actively involved in big data with an interest in facilitating the positive impacts of big data externalities. We coded the Likert scale for knowledge (1 to 5 scale), interest (1 to 5 scale), and position ( -2 to +2 scale) levels indicated by the stakeholder individuals. Figure 9 shows the average characteristics of stakeholders to cross the case studies.

\begin{tabular}{|c|c|c|c|c|c|}
\hline & Very low & Low & Average & High & Very high \\
\hline Crisis & & & & 2 & 5 \\
\hline Culture & & & & & 12 \\
\hline Energy & & & & & 7 \\
\hline Environment & & 1 & 1 & 2 & 2 \\
\hline Healthcare & & & & & 10 \\
\hline Smart City & & & & 1 & 3 \\
\hline Transport & & & & & 10 \\
\hline
\end{tabular}

Fig. 6 Knowledge level of stakeholder individuals in BYTE case studies 


\begin{tabular}{|c|c|c|c|c|c|}
\hline & Opponent & $\begin{array}{l}\text { Moderate } \\
\text { Opponent }\end{array}$ & Neutral & $\begin{array}{l}\text { Moderate } \\
\text { Supporter }\end{array}$ & Supporter \\
\hline Crisis & & & & 2 & 6 \\
\hline Culture & 1 & & & & 13 \\
\hline Energy & & & & 5 & 2 \\
\hline Environment & & & & 3 & 3 \\
\hline Healthcare & & & & & 8 \\
\hline Smart City & & & & 2 & 2 \\
\hline Transport & & & & & \\
\hline
\end{tabular}

Fig. 7 Position of stakeholder individuals in support of the BYTE case studies

\begin{tabular}{r|r|c|c|c|c|}
\multicolumn{1}{c}{} & \multicolumn{1}{c}{ Very low } & \multicolumn{1}{c}{ Low } & \multicolumn{1}{c}{ Average } & \multicolumn{1}{c}{ High } & \multicolumn{1}{c}{ Very high } \\
\cline { 2 - 6 } Crisis & & & & 2 & 5 \\
\cline { 2 - 6 } Culture & & & & 1 & 12 \\
\cline { 2 - 6 } Energy & & & 3 & 3 & 2 \\
\cline { 2 - 6 } Environment & & & 3 & & 3 \\
\cline { 2 - 6 } Healthcare & & & & & 9 \\
\cline { 2 - 6 } Smart City & & & & 1 & 3 \\
\cline { 2 - 6 } Transport & & 3 & 1 & 1 & 5 \\
\cline { 2 - 6 } & & & & & \\
\cline { 2 - 6 } & & & & &
\end{tabular}

Fig. 8 Interest of stakeholder individuals in BYTE case studies

\begin{tabular}{|r|c|c|c|} 
Knowledge & Interest & Position \\
\hline Culture & 4.71 & 4.71 & 1.71 \\
\hline Energy & 5 & 4.92 & 2 \\
\hline Environment & 3.83 & 4 & 1.28 \\
Healthcare & 5 & 4 & 1.5 \\
Smartcity & 4.75 & 4.75 & 1.5 \\
\hline Transport & 5 & 3.8 & \\
\hline
\end{tabular}

Fig. 9 Average levels of knowledge, support position, and interest of stakeholders

\subsection{Stakeholder Influence}

Identification of stakeholder influence is an important step to classify stakeholders. By understanding a stakeholder's influence, we can better understand their relationships within the case study. Influence can be understood in terms of the amount of power a stakeholder has over the system. Influence can be both formal and informal. Formal influence is primarily based on rules or rights as laid down in legislation or formal agreements (i.e. law and rights to enforce the law, or usage rights). Informal influences are based on other factors such as interest groups or non-governmental organisations that can mobilise media, use resources, or lobby to put pressure on the ecosystem. 
Table 2 Influence of different data stakeholders based on case studies

\begin{tabular}{|c|c|c|}
\hline Stakeholder & Type & Influence \\
\hline \multicolumn{3}{|l|}{ Environment case study } \\
\hline EC (European Commission) & Governmental organisation & High \\
\hline EEC (European Economic Committee) & Governmental organisation & High \\
\hline EPA (Environmental Protection Agency) & Governmental organisation & High \\
\hline EuroGeoSurveys & Governmental organisation & Medium \\
\hline EUStatCen & Governmental organisation & Medium \\
\hline IEEE & Not-for-profit organisation & High \\
\hline UNEP & International organisation & Medium \\
\hline \multicolumn{3}{|l|}{ Crisis management case study } \\
\hline RICC & Research institute & Medium \\
\hline ICRC & International organisation & Medium \\
\hline OCHA & International organisation & Medium \\
\hline \multicolumn{3}{|l|}{ Cultural case study } \\
\hline National cultural heritage institution & Governmental organisation & Low \\
\hline National data aggregator & Governmental organisation & Medium \\
\hline Pan-European cultural heritage organisation & International organisation & Medium \\
\hline National policy office & Governmental organisation & High \\
\hline Citizens & Citizens & Low \\
\hline Educational institutions & Educational institution & Medium \\
\hline Open data advocates & Non-governmental organisation & Medium \\
\hline Private sector cultural data consultancy & Small \& medium Enterprise & Medium \\
\hline \multicolumn{3}{|l|}{ Energy case study } \\
\hline StatOil & Large corporation & Medium \\
\hline ConcoPhillips & Large corporation & Medium \\
\hline Lundin & Large corporation & Medium \\
\hline EniNorge & Large corporation & Medium \\
\hline Supplier & Large corporation & Low \\
\hline Norwegian Petroleum Directorate & Governmental organisation & Medium \\
\hline \multicolumn{3}{|l|}{ Health case study } \\
\hline Public sector health research initiative & Research institute & High \\
\hline Geneticists & Skilled professionals & Medium \\
\hline Clinicians & Skilled professionals & Medium \\
\hline Data scientists & Skilled professionals & High \\
\hline Pharmaceutical companies & Large corporation & Medium \\
\hline Translational medicine specialists & Experts & Medium \\
\hline Public health research initiative & Research institute & High \\
\hline NHS regional genetics laboratory & Government organisation & Medium \\
\hline Charity organisations & Charity organisations & Low \\
\hline Privacy and data protection policymakers & Policymakers & High \\
\hline Privacy and data protection policy lawyers & Skilled professionals & Medium \\
\hline Citizens & Citizens & Low \\
\hline Patients and immediate family members & Citizens & Low \\
\hline
\end{tabular}


Table 2 (continued)

\begin{tabular}{|c|c|c|}
\hline Stakeholder & Type & Influence \\
\hline \multicolumn{3}{|l|}{ Transport case study } \\
\hline Established ship owner & Large corporation & Medium \\
\hline New ship owner & Large corporation & Low \\
\hline European yard & Governmental organisation & High \\
\hline Navigation equipment supplier & Large corporation & Medium \\
\hline Machinery subsystem supplier & Large corporation & Medium \\
\hline Shipping association & Not-for-profit corporation & Low \\
\hline Maritime consulting company & Small \& medium enterprise & Medium \\
\hline Classification society & Not-for-profit corporation & Medium \\
\hline National Coastal Authority & Governmental organisation & Low \\
\hline \multicolumn{3}{|l|}{ Utilities/smart cities case study } \\
\hline European City & Governmental organisation & Medium \\
\hline Technology provider - SME & Small \& medium enterprise & Medium \\
\hline Technology provider & Not-for-profit corporation & Medium \\
\hline Technology provider \& research & Large corporation & High \\
\hline
\end{tabular}

This section provides a cross-case analysis of the power or influence of the stakeholders in the data ecosystem. This cross-case analysis was performed using a questionnaire, interviews, and workshops conducted as part of the BYTE project. We provide an analysis of stakeholders in terms of their influence on the data ecosystem and its externalities (Table 2). This analysis is performed at the group level of stakeholders. The objective of the analysis is to classify stakeholder groups and organisations according to their capability to affect or influence the data ecosystem. In general, civil society organisations and citizens have low to medium influence on data ecosystems, which is a cause for concern. This is also true for stakeholders in the cultural sector. To address this, better incentives and a better engagement approach are required for these stakeholders to meaningfully contribute to the big data community.

\section{Summary}

This chapter analysed the stakeholders in European big data with the help of sectoral case studies. It also examined the stakeholder relationships within and between different categories. Although preliminary, the results of the analysis indicate that, in general, the innovation in data technologies is driven by sector-specific demands. Environment, energy, and smart city sectors show maturity in data technologies. Transport, healthcare, crisis management, and culture sectors require more engagement with the big data community for better adoption of useful technologies and influencing the European policy to address their needs. 
Acknowledgements We thank the participants of the BYTE project focus groups and workshops for their insightful contributions. This work was funded by the European Union's Seventh Framework Programme FP7/2007-2013/CSA under grant agreement $n^{\circ}$ 619551. This publication has emanated from research supported in part by a research grant from Science Foundation Ireland (SFI) under Grant Number SFI/12/RC/2289_P2, co-funded by the European Regional Development Fund.

\section{References}

Cuquet, M., Vega-Gorgojo, G., Lammerant, H., et al. (2017). Societal impacts of big data: Challenges and opportunities in Europe. arXiv:170403361

Curry, E. (2016). The Big data value chain: Definitions, concepts, and theoretical approaches. In J. M. Cavanillas, E. Curry, \& W. Wahlster (Eds.), New horizons for a data-driven economy: A roadmap for usage and exploitation of big data in Europe. New York: Springer.

Freeman, R. E. (1984). Strategic management: A stakeholder approach.

Grimble, R., \& Wellard, K. (1997). Stakeholder methodologies in natural resource management: A review of principles, contexts, experiences and opportunities. Agricultural Systems, 55, 173-193.

Grimble, R., Chan, M.-K., Aglionby, J., \& Quan, J. (1995). Trees and trade-offs: A stakeholder approach to natural resource management. Gatekeeper Series, 52, 18.

Lammerant, H., De Hert, P., Lasierra Beamonte, N., et al. (2015). Horizontal analysis of positive and negative societal externalities.

Manyika, J., Chui, M., Brown, B., et al (2011). Big data: The next frontier for innovation, competition, and productivity. McKinsey Global Institute.

Miles, S. (2012). Stakeholder: Essentially contested or just confused? Journal of Business Ethics. https://doi.org/10.1007/s10551-011-1090-8

Nolan, R., \& McFarlan, F. W. (2005). Information technology and the board of directors. Harvard Business Review, 96-106(157), 83.

Pouloudi, A. (1999). Aspects of the stakeholder concept and their implications for information systems development. Proceedings of the 32nd Annual Hawaii International Conference on Systems Sciences. https://doi.org/10.1109/HICSS.1999.772776

Reed, M. S., Graves, A., Dandy, N., et al. (2009). Who's in and why? A typology of stakeholder analysis methods for natural resource management. Journal of Environmental Management, 90 , 1933-1949. https://doi.org/10.1016/j.jenvman.2009.01.001

Rogers, E. M. (1962). Diffusion of innovations. The Free Press.

Weyer, M. V. (1996). In an ideal world. Management Today, 34-38.

Yin RK (2013) Case Study Research: Design and Methods. SAGE Publications 26:93-96. https:// doi.org/10.1017/CBO9781107415324.004 
Open Access This chapter is licensed under the terms of the Creative Commons Attribution 4.0 International License (http://creativecommons.org/licenses/by/4.0/), which permits use, sharing, adaptation, distribution and reproduction in any medium or format, as long as you give appropriate credit to the original author(s) and the source, provide a link to the Creative Commons licence and indicate if changes were made.

The images or other third party material in this chapter are included in the chapter's Creative Commons licence, unless indicated otherwise in a credit line to the material. If material is not included in the chapter's Creative Commons licence and your intended use is not permitted by statutory regulation or exceeds the permitted use, you will need to obtain permission directly from the copyright holder. 